The retrospective chart review of 110 patients with $\mathrm{T} 2$ supraglottic cancer who underwent radiotherapy was performed to correlate tumor volume with other prognostic factors and to analyze its impact on treatment results. Patients with involved nodes, poor histopathological tumor differentiation, or hemoglobin concentration $\leq 14.3 \mathrm{~g} / \mathrm{dl}$ had significantly larger tumors. Patients with large tumors had significantly lower 5-year local control rate, overall survival rate and presented significantly higher risk of nodal involvement and the ratio of poor histopathological differentiation of the tumor. Tumor volume significantly impacts radiotherapy outcome and should be considered to optimize treatment strategy for patients with T2 supraglottic cancer.

Key words: T2 laryngeal cancer, tumor volume, radiotherapy, head and neck cancer.

Contemp Oncol (Pozn) 2014; 18 (6): 429-435 DOI: $10.511 /$ wo.2014.44542

\section{The effect of tumor volume on radiotherapy outcome and correlation with other prognostic factors in patients with $\mathrm{T} 2$ supraglottic cancer}

Tomasz W. Rutkowski ${ }^{1}$, Bogusław Maciejewski², Zofia Kołosza ${ }^{3}$,

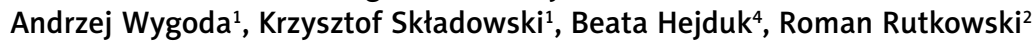

${ }^{1}$ Department of Radiotherapy and Chemotherapy, Maria Sklodowska-Curie Memorial Cancer Centre and Institute of Oncology, Gliwice Branch, Poland

${ }^{2}$ Department of Radiotherapy, Maria Sklodowska-Curie Memorial Cancer Centre and Institute of Oncology, Gliwice Branch, Poland

${ }^{3}$ Department of Cancer Epidemiology, Maria Sklodowska-Curie Memorial Cancer Centre and Institute of Oncology, Gliwice Branch, Poland

${ }^{4}$ Department of Medical Diagnostic, Maria Sklodowska-Curie Memorial Cancer Centre and Institute of Oncology, Gliwice Branch, Poland

\title{
Introduction
}

Treatment results of patients suffering from $\mathrm{T} 2$ supraglottic cancer are relatively good and radiotherapy $(\mathrm{RT})$ is often considered as a primary treatment modality [1-3]. Some of T2 supraglottic tumors present however worse prognosis and the tumor size, among other factors, may be the predictor of such clinical course of disease. For these cases additional therapy than RT alone is possibly needed. The prognostic role of tumor volume (TV) for $\mathrm{RT}$ of laryngeal cancer is generally known $[4,5]$. Up till now however it has been difficult to draw clinically useful conclusions on its value for selected, early supraglottic tumors because most published results were based on relatively small groups of patients with different $T$ stages and various primary tumor localization reported together. Our previous analysis was limited only to T2 laryngeal tumors (glottic and supraglottic) treated exclusively with RT. Besides a significant influence of TV on treatment outcome in that group of patients, TV was found to be strongly related to some other prognostic factors. Moreover, volumes of supraglottic tumors appeared to be higher than glottic ones [6]. It suggested that relationship between TV and other factors may by even stronger expressed for supraglottic tumors and needs to be analyzed independently.

The aim of this study was to assess the impact of TV on RT outcome and to determinate the relationship between TV and other prognostic factors in patients with $\mathrm{T} 2$ supraglottic cancer treated exclusively with RT.

\section{Material and methods}

Records of 110 patients who underwent RT between 2002 and 2010 for previously untreated T2 supraglottic squamous cell carcinoma at the Maria Sklodowska-Curie Memorial Cancer Center and Institute of Oncology, Gliwice Branch, Poland, were reviewed. Five patients had chemotherapy concomitantly with RT and due to this were excluded from further analysis. The group consists of $75(71 \%)$ men and 30 (29\%) women with a mean age of 60 years (range: 39-82 years). In 34 (32\%) patients, regional, neck lymph nodes were involved $(\mathrm{N}+)$. There were $12(11 \%)$ patients with $\mathrm{N} 1$ and $22(21 \%)$ patients with N2 stage of disease. No nodal bulky disease was observed in this group. 
There were 23 (22\%) and 47 (45\%) well (G1) and poorly (G2, G3) histopathologically differentiated tumors, respectively. In 35 (33\%) patients, no data on this was available. All of the patients were treated exclusively with 3D-RT using intensity-modulated radiotherapy (IMRT) in most of cases. The primary tumor (gross tumor volume - GTV) was treated with a minimum of $1 \mathrm{~cm}$ margin (PTV) due to laryngeal motion. Clinical target volume (CTV) of high dose involved majority of the larynx and involved nodes with $1 \mathrm{~cm}$ margin (CTV1). Remaining nodal levels were encompassed in CTV2. Three dose fractionation schedules had been used in analyzed group of patients. In 15 (14\%) patients 62.5 Gy was given in 25 fractions for CTV1 (62.5 Gy/25 fx) and 45 Gy/18 fx for CTV2 (five fractions per week). In 68 (65\%) patients 68.4-72 Gy/38-40 fx was given as a concomitant boost ( 7 fractions per week) for CTV1 and 54 Gy/30 fx was given for CTV2 (5 fractions per week). In 21 (20\%) patients 70-72 Gy/35-36 fx and 50 Gy/25 fx was given for CTV1 and CTV2 respectively (five fractions per week). In one patient planned total dose (TD) was not reached due to cardiac problems. For the analysis TD was recalculated as normalized total dose (NTD) if given in 2.0 Gy fractions using L-Q model (with $\alpha / \beta$ value of $10.0 \mathrm{~Gy}$ ).

Patients were immobilized using a commercially available thermoplastic mask that covered the head and neck. The TV was manually contoured on pretreatment, planning, contrast-enhanced CT scans acquired in 1-3 mm slices. Additional information concerning tumor spread or superficial infiltration was obtained on endoscopic laryngeal examination completing volume to be contoured. Volumetric three-dimensional measurements $\left(\mathrm{cm}^{3}\right)$ of contoured structures were calculated by the Varian Treatment Planning System (Eclipse) volume algorithm. Only the primary tumor was involved in the TV. Patients were divided into 4 groups according to TV quartiles: TV1 $\left(<2.6 \mathrm{~cm}^{3} ; n=\right.$ $=27)$, TV2 $\left(>2.6-\leq 5.6 \mathrm{~cm}^{3} ; n=26\right)$, TV3 $\left(>5.6-\leq 9.7 \mathrm{~cm}^{3}\right.$; $n=26)$ and TV4 $\left(>9.7 \mathrm{~cm}^{3}\right)$.

The median hemoglobin $(\mathrm{Hb})$ concentration before RT was $14.3 \mathrm{~g} / \mathrm{dl}$. Data concerning Hb concentration was lacking in 10 (9.5\%) patients. Symptoms duration (SD) was calculated as the time from the first sign of disease that had been noticed by the patient to the moment of the admission to our Cancer Center. Symptoms included both subjective as: pain, digestive problems, dyspnoea and objective ones like tumor on the neck, cough, hoarseness. Median and mean duration of SD was 5 and 8 months (range: 1-60 months). For 13 (12\%) patients, data on this was lacking.

\section{Statistical methods}

The Mann-Whitney test was used for intergroup comparisons of the continuous variables. The distributions of the discrete variables in various groups of patients were compared with Fisher's exact test or Pearson's $\chi^{2}$ test.

The role of TV ( 4 groups) as the risk factor of regional spread of disease were verified by calculating odds ratios (ORs) together with 95\% confidence intervals.

Confidence intervals on the OR were estimated using the Woolf method. Probabilities of overall survival (OS) and local control (LC) defined as a primary tumor control were estimated from the end of RT using the Kaplan-Meier product-limit estimate and were compared by the log-rank test.

Potential prognostic factors for OS and LC were evaluated using Cox proportional hazards regression. For each variable the assumption of proportional hazards were tested using test based on Schoenfeld residuals (phtest STATA). For LC (apart from continuous TV) and OS all variables satisfied the proportionality assumption.

\section{Results}

After median follow-up of 4.9 years 5 -year LC and OS was $72 \%$ and $52 \%$ respectively. Local failure appeared as $13(12 \%)$ persistent tumors and 13 (12\%) recurrent tumors. Local recurrences developed in the median time of 16 months (range: 12-67 months). There were 5 regional failures. One of them was isolated, three were found concomitantly with local failure, one was found 43 months after local recurrence. Distant metastases were found in three patients after 11, 28 and 59 months after RT completion and in two cases it was the only reason of failure. In the next three patients secondary primary tumor was diagnosed in 12, 23 and 46 months after RT completion and in two of them it was the only reason of failure. At the time of analysis 46 (44\%) patients died.

\section{Treatment outcome according to tumor volume \\ Local control}

Median TV of patients locally cured was $5.5 \mathrm{~cm}^{3}$ and was lower than TV of patients who locally failed $-7.7 \mathrm{~cm}^{3}$ $(p=0.2)$. When categorized according to median, there was no significant influence of TV on LC (Fig. 1A). Patients from TV4 group had significantly lower 5 -year LC rate (46\% vs. $77 \%, p=0.03$ ) (Fig. 1C) and almost 2.5 times higher risk of local failure than patients with smaller tumors (Table 1 ).

\section{Overall survival}

Median TV of patients who died during follow-up was $7.8 \mathrm{~cm}^{3}$ and was significantly higher than TV of those who remained alive during analysis $-5.0 \mathrm{~cm}^{3}(p=0.003)$. Tumor volume as a continuous variable significantly influenced OS $(p=0.0006)$. When categorized according to median, patients with TV $>5.6 \mathrm{~cm}^{3}$ had significantly lower 5 -year OS comparing to those with smaller tumors (Fig. 1B). Patients from TV4 group had significantly lower 5-year OS rate, comparing to patients with smaller tumors (18\% vs. $63 \%, p=0.0004$ ) (Fig. 1D) and had over 3 times higher risk of death than patients with smaller tumors (Table 1 ).

\section{Other relationship of tumor volume}

Patients with $\mathrm{N}+$ had significantly higher TV comparing to patients with NO $\left(7.6 \mathrm{~cm}^{3}\right.$ vs. $\left.4.8 \mathrm{~cm}^{3}, p=0.01\right)$. Significantly more frequent occurrence of $\mathrm{N}+$ in patients with TV3 and TV4 compared to patients with TV1 $(O R=4.22$ 95\% Cl: $1.13-15.73, p=0.028$ and $\mathrm{OR}=4.93,95 \% \mathrm{Cl}: 1.33-$ $18.31, p=0.014$ respectively) was found (Table 2 ). 

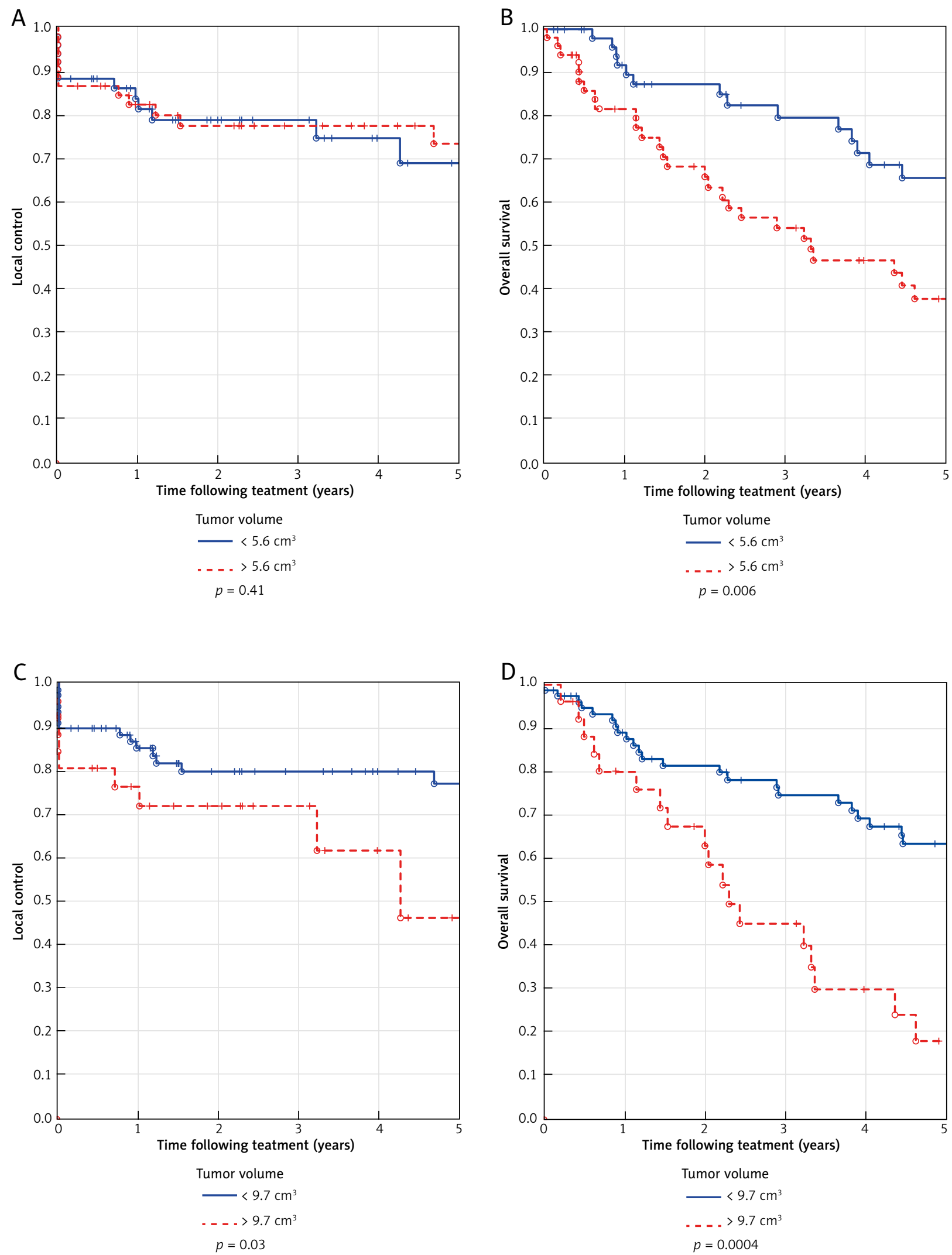

Fig. 1. Probability of local control (A, C) and overall survival (B, D) of patients with T2 supraglottic cancer in dependence on value of tumor volume. Data are stratified according to quartiles into two groups: below the median (TV $\leq 5.6 \mathrm{~cm}^{3}$, solid thin line) and above the median (TV $>5.6 \mathrm{~cm}^{3}$, dashed line) (A, B) and below the third quartile (TV $\leq 9.7 \mathrm{~cm}^{3}$, solid thin line) and above the third quartile (TV $>9.7 \mathrm{~cm}^{3}$, dashed line) (C, D) 
Table 1. Results of local control and overall survival Cox analysis

\begin{tabular}{lccccc} 
& & Local control & & \multicolumn{2}{c}{ Overall survival } \\
TV $\left(\mathrm{cm}^{3}\right)$ & $\mathrm{HR}$ & $95 \% \mathrm{Cl}$ & $p$ value & $\mathrm{HR}$ & $95 \% \mathrm{Cl}$ \\
$\leq 9.7$ & 1 & - & - & 1 & - \\
$>9.7$ & 2.43 & $1.07-5.49$ & 0.03 & 3.13 & $1.71-5.73$
\end{tabular}

TV -tumor volume, categorized acc. to upper quartile $=9.7 \mathrm{~cm}^{3}$

Table 2. Relative risk of nodal spread according to TV

\begin{tabular}{|c|c|c|c|c|c|c|c|}
\hline $\operatorname{TV}\left(\mathrm{cm}^{3}\right)$ & NO & $\%$ & $\mathrm{~N}+$ & $\%$ & $\begin{array}{c}\text { OR } \\
(\mathrm{N}+\text { vs. NO) }\end{array}$ & $95 \% \mathrm{Cl}$ & $p$ value \\
\hline$\leq 2.5$ & 23 & 85.2 & 4 & 14.8 & 1 & - & - \\
\hline$>2.5-\leq 5.6$ & 19 & 73.1 & 7 & 26.9 & 2.12 & $0.54-8.34$ & 0.281 \\
\hline$>5.6-\leq 9.7$ & 15 & 57.7 & 11 & 42.3 & 4.22 & $1.13-15.73$ & 0.028 \\
\hline$>9.70$ & 14 & 53.8 & 12 & 46.2 & 4.93 & $1.33-18.31$ & 0.014 \\
\hline
\end{tabular}

$T V$-tumor volume; N1 - regional nodes involved; NO-regional nodes not involved

Table 3. Relative risk of histopathological differentiation according to tumor volume (TV), G1-well, G2 + G3-poorly histopathologically differentiated tumors

\begin{tabular}{|c|c|c|c|c|c|c|c|}
\hline $\mathrm{TV}\left(\mathrm{cm}^{3}\right)$ & G1 & $\%$ & $\mathrm{G} 2+\mathrm{G} 3$ & $\%$ & $\begin{array}{c}\text { OR } \\
(\mathrm{G} 2+\mathrm{G} 3 \text { vs. } \mathrm{G} 1)\end{array}$ & $95 \% \mathrm{Cl}$ & $p$ value \\
\hline$\leq 2.5$ & 11 & 47.8 & 9 & $19.1 \%$ & 1 & - & - \\
\hline$>2.5-\leq 5.6$ & 5 & 21.7 & 12 & $25.5 \%$ & 2.93 & $0.70-12.29$ & 0.123 \\
\hline$>5.6-\leq 9.7$ & 5 & 21.7 & 12 & $25.5 \%$ & 2.93 & $0.70-12.29$ & 0.123 \\
\hline$>9.7$ & 2 & 8.7 & 14 & $29.8 \%$ & 4.93 & $1.22-59.92$ & 0.014 \\
\hline
\end{tabular}

Test of homogeneity (equal odds): $\chi^{2}(3)=7.52 ; p=0.0569$; Score test for trend of odds: $\chi^{2}(1)=6.67 ; p=0.0098$

Table 4. Changing of hemoglobin concentration according to TV

$\begin{array}{lccc}\text { TV }\left(\mathrm{cm}^{3}\right) & n & \text { Median } \mathrm{Hb} & p \text { value } \\ \leq 2.5 & 22 & 14.9 & \\ >2.5-\leq 5.6 & 25 & 14.5 & 0.78 \\ >5.6-\leq 9.7 & 25 & 14.2 & 0.56 \\ >9.7 & 23 & 13.6 & 0.01\end{array}$

Table 5. Results of multivariate analysis for local control

$\begin{array}{lccc}\text { Variable } & \text { HR } & 95 \% \mathrm{Cl} & p \text { value } \\ \begin{array}{l}\text { SD } \\ \text { ( } \leq 5 \text { vs. }>5 \text { months })\end{array} & 2.25 & 0.99-5.10 & 0.05 \\ \begin{array}{l}\text { NTD } \\ (\leq 67.3 \text { vs. }>67.3 \mathrm{~Gy})\end{array} & 2.54 & 1.12-5.75 & 0.02 \\ \begin{array}{l}\text { TV } \\ \left(\leq 9.7 \text { vs. }>9.7 \mathrm{~cm}^{3}\right)\end{array} & 2.13 & 0.92-4.96 & 0.07\end{array}$

Table 6. Results of multivariate analysis for overall survival

$\begin{array}{lccc}\text { Variable } & \text { HR } & 95 \% \mathrm{Cl} & p \text { value } \\ \mathrm{Hb}(\mathrm{g} / \mathrm{dl}) & 0.76 & 0.60-0.95 & 0.02 \\ \mathrm{TV}\left(\mathrm{cm}^{3}\right) & 1.08 & 1.02-1.13 & 0.002\end{array}$

TV-tumor volume; $\mathrm{Hb}$ - hemoglobin
Patients with G2, G3 tumors presented significantly higher TV comparing to patients with G1 tumors $\left(6.5 \mathrm{~cm}^{3}\right.$ vs. $3.6 \mathrm{~cm}^{3}, p=0.006$ ). There was significantly more frequent occurrence of G2, G3 tumors in TV4 patients comparing to TV1 patients ( $\mathrm{OR}=4.93,95 \% \mathrm{Cl}: 1.22-59.92$, $p=0.014$ ) (Table 3).

Patients with SD longer than 5 months presented almost two times lower TV than patients with shorter SD (3.9-7.4 $\left.\mathrm{cm}^{3}, p=0.03\right)$. Patients with $\mathrm{Hb} \leq 14.3 \mathrm{~g} / \mathrm{dl}$ had significantly larger TV than those with higher $\mathrm{Hb}\left(7.8 \mathrm{~cm}^{3}\right.$ vs. $4.2 \mathrm{~cm}^{3}, p=0.002$ ). There was trend of decreasing median $\mathrm{Hb}$ with increasing TV. Patients from TV4 group had significantly lower median Hb than TV1 patients (Table 4).

\section{Treatment outcome according to other variables}

Results of univariate analysis shown that when categorized, NTD above 67.3 Gy (median) was correlated with significantly lower $\mathrm{LC}$ rate $(\mathrm{HR}=2.5, p=0.02)$. As a continuous variable $\mathrm{Hb}$ was significantly related to OS ( $p=$ $=0.002$ ). While categorized, $\mathrm{Hb}$ above median did not influence $L C$ rate, but was correlated with significantly higher 5-year OS rate (Fig. 2). In multivariate analysis only NTD remained significantly related to LC (Table 5). Hemoglobin together with TV remained significantly related to OS. For $1 \mathrm{~g} / \mathrm{dl}$ increase of $\mathrm{Hb}$ concentration, $24 \%$ decreased in the risk of death was supposed. For $1 \mathrm{~cm}^{3}$ increase of TV, $8 \%$ increase in the risk of death was supposed (Table 6). 

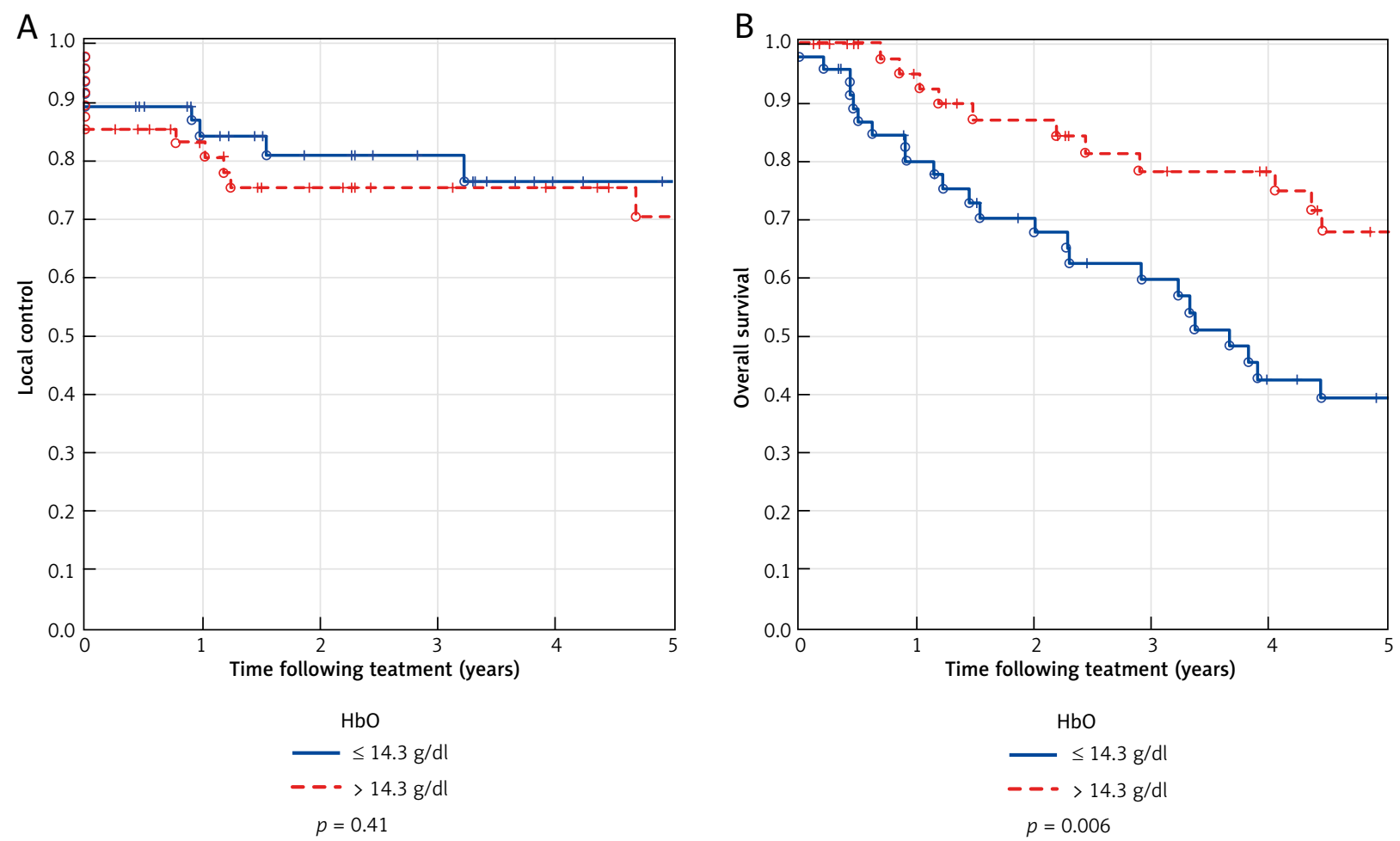

Fig. 2. Probability of local control (A) and overall survival (B) of patients with T2 supraglottic cancer in dependence on hemoglobin concentration. Data are stratified into two groups: below the median ( $\mathrm{Hb} \leq 14.3 \mathrm{~g} / \mathrm{dl}$, solid thin line) and above the median (Hb >14.3 g/dl, dashed line)

\section{Discussion}

Several studies has been published in which prognostic role of TV in patients with laryngeal cancer was described [7-11]. Majority of these papers reported small and heterogeneous groups of patients involving both, glottic and supraglottic tumors of various T-stage. Along with that, various cut-off values of TV were proposed to be prognostic but practical conclusions could hardly be drawn, especially for selected, single T-staged tumors. Comprehensive review of published data on this issue can be found elsewhere [4]. In this study the role of TV for patients with T2 supraglottic cancers treated exclusively with RT was analyzed.

So far no significant influence of TV on OS rate in patients with supraglottic cancer has been reported. We found such relation which seems to be even stronger than for $L C$ rate.

The substantial range of TV in a single T-stage of supraglottic tumors is a result of anatomy based, for surgeon rather than for radiation oncologist dedicated, criteria of TNM classification system. The importance of TV for results of RT may be explained by the fact that larger tumors require larger doses for cure. The interpretation of this is that the number of tumor clonogens requiring sterilization increases with TV [12-14]. Both, the large infiltration of supraglottis involving base of the tongue and the small one, but involving at least two subsities of larynx without its fixation are T2 tumors. With no doubt the higher TD is needed to eradicate tumor in previous situation. The analysis of the relationship between TD and initial TV has shown that within the $\mathrm{T} 2$ glottic cancer larger tumors with
TV of about $5 \mathrm{~cm}^{3}\left(2-2.5 \mathrm{~cm}\right.$ in diameter with $10^{10}$ cancer cells) need an extra 6.5 Gy to achieve similar, 3-year LC as small tumors with $0.5 \mathrm{~cm}^{3}\left(\sim 1 \mathrm{~cm}\right.$ in diameter with $10^{9} \mathrm{can}$ cer cells) [15]. We did not find the relation between TD and TV in this study, although TD was negatively correlated with treatment outcome. It may be explained by the assumption that higher radiation doses had been prescribed for larger tumors but it did not compensate greater number of clonogenic tumor cells. It may suggest that despite early disease according to TNM classification system, for larger tumors additional treatment than RT alone should be considered.

Relatively high TV of some supraglottic tumors may be, beside anatomical localization, the reason of higher risk of regional spread of disease. Some data respecting head and neck tumors indicated the relation between TV and the risk of nodal spread [16], other did not confirm this [17]. It has been concluded that TV is not universally prognostic factor of the risk of nodal spread, but depends on tumor localization $[18,19]$. We found that for supralaryngeal tumors the risk of regional spread increases significantly with TV. To our knowledge, it is the first time that relationship between TV and the risk of nodal spread for patients with laryngeal cancer was assessed. Due to this, for larger TV even with clinically NO disease, additional diagnostic procedure prior to RT or close follow up after treatment should be considered.

Benzen et al. [12] analyzing data on the volume-cure relationship for various tumors including HNC, concluded that the effect of TV on tumor cure probability is less that would be predicted from a simple proportionate increase 
in tumor clonogen number with TV. Such interpretation of the TV effect should be probably supplemented with additional volume-related factors as clonogenic fraction, hypoxia, clonal radioresistance and intracellular communication. In a view of this assumption, the relationship between TV and other factors of potential prognostic value were analyzed in the study.

Although there is an evidence that tumor hypoxia adversely affects locoregional tumor control and survival in patients with head and neck cancer (HNC), it is still not well established how hypoxic fraction of the tumor could be measured. Results of some studies suggest that TV may, in some way, predict effectiveness of RT both, reflecting status of tumor oxygenation and correlating with $\mathrm{Hb}$ concentration.

Hypoxic cells are suspected to be radioresistant. Experimental data have demonstrated that hypoxic cells can be found around or in the necrotic part of the tumor [20]. Kuhnt et al. [21] found that TV was significantly correlated to CT-based amount of necrosis (necrotic volume) whereas T-stage was not. It appeared that tumors with smaller amount of necrosis $\left(<4 \mathrm{~cm}^{3}\right)$ had a good prognosis regardless of type of the treatment, whereas tumors with larger amount of necrosis $\left(\geq 4 \mathrm{~cm}^{3}\right)$ had a significantly better outcome if treated with CHRT comparing to RT alone (2-year event-free survival $70 \%$ vs. $0 \%$ respectively, $p<0.0008)$. According to authors, the superiority of CHRT may be explained by radiosensitization of radioresistant cells. To quantify approximately the amount of hypoxic tissue which should be correlated to the total number of hypoxic cells in the tumor, hypoxic subvolume (hTV) as the percentage of $\mathrm{pO}_{2}$-value below $5 \mathrm{~mm} \mathrm{Hg}$ multiplied by the TV, as a new parameter was proposed by Stadler et al. [22]. It also has been found that total amount of hypoxic tissue determined by hTV influenced the prognosis of HNC patients. Additionally, Dunst et al. [23] defined nonhypoxic TV as a difference between the TV and hTV. It appeared that patients who were alive at the time of analysis had significantly lower mean TV: $34 \mathrm{~cm}^{3}$ vs. $54 \mathrm{~cm}^{3}(p=0.01)$ and mean hTV: $11 \mathrm{~cm}^{3}$ vs. $22 \mathrm{~cm}^{3}(p=0.009)$ than those who died. In a multivariate analysis the hTV was strong and independent prognostic factor for survival $(p=0.001)$ and more important than TV $(p=0.02)$ whereas the nonhypoxic TV had no impact on prognosis $(p=0.3)$. We did not analyzed the amount of necrosis but probably it would be uncommon due to relatively low TV in our set of patients. Considering however the correlation between quantity of necrosis and TV, significant amount of hypoxic tumor cells effecting with increased radioresistance should be supposed in larger tumors.

Hemoglobin concentration appeared to be an independent prognostic factor for patients with laryngeal cancer treated with RT [6, 24]. Hereby we also found that patients with lower $\mathrm{Hb}$ concentration presented significantly poorer OS rate. Beside this, the negative relationship between $\mathrm{Hb}$ and TV was found what is in concordance with our previous observation for both, glottic and supraglottic tumors [6]. Negative correlation between $\mathrm{Hb}$ concentration and TV was also found by Stadler [22]. Among other assumptions, it has been proposed that $\mathrm{Hb}$ is a surrogate marker for tu- mor hypoxia but still few data exist to test this hypothesis. Nordsmark et al. [25] found both, $\mathrm{Hb}$ and tumor hypoxia as significant but independent prognostic factors for locoregional tumor control for HNC patients after RT, and $\mathrm{Hb}$ concentration was not a surrogate marker of tumor hypoxia. From another point of view, as it was mentioned above, $T V$ remains in the relation to the amount of hypoxic tissue. If so, TV may, in some way, be a determinant of $\mathrm{Hb}$ concentration and tumor hypoxia independently. Decreasing of $\mathrm{Hb}$ concentration due to tumor bleeding is rather unusual for early laryngeal tumors ( $\mathrm{Hb}$ concentration < $12 \mathrm{~g} / \mathrm{dl}$ was observed only in less than $5 \%$ of patients in this group). Irrespective of anemia reason, due to low $\mathrm{Hb}$, early disease presented by large TV seems to be of poor prognosis.

Another predictive aspect of TV was described by Kats et al. [26]. He reported that among patients who underwent total larygectomy mean TV of those with and without thyroid cartilage penetration was $60.1 \mathrm{~cm}^{3}$ and $28 \mathrm{~cm}^{3}$ respectively $(p=0.004)$. When patients were divided into 3 groups according to TV $\left(<25 \mathrm{~cm}^{3}, 25-50 \mathrm{~cm}^{3},>50 \mathrm{~cm}^{3}\right)$ the rates of thyroid cartilage penetration were $23 \%, 17 \%$, $78 \%$, respectively $(p=0.003)$. Authors recommended incorporation of TV assessment into diagnostic formula for predicting thyroid cartilage penetration and selecting patients who have lower chance of benefiting from laryngeal preservation.

Some data on prognostic role of histopathological tumor differentiation for patients with laryngeal cancer could be found in literature and few if any on the relation between symptoms duration before treatment on its results. We found that histopathologically poorly differentiated tumors presented significantly higher TV and the probability of occurrence of such tumor increase significantly with the TV. Chung et al. [27] also found that the more poorly differentiated the primary laryngeal tumor, the more advanced was disease and higher the incidence of cervical node metastases. Lohynska et al. [28] stated that 2 or more negative prognostic factors including high grade of tumor was associated with significantly higher relapse rate for early laryngeal cancer. Patients with shorter symptoms duration had larger TVs. Patients with SD $\leq 5$ months had reduced $L C$ ratio and over 2 times higher risk of local failure. This observation is in concordance with our pervious report [6] but had not been described before. Beside the primary tumor localization in the supraglottic area, also rapid tumor proliferation and fast progression of TV may be the reason of early symptoms. The assumption that poorly differentiated tumors rapidly proliferate turning into larger tumors could not be excluded.

The are some limitations of this research that may restrict the conclusions that could be drawn from the study. Retrospective character and some, mainly tumor-related data, is lacking. Despite of this our results showed that TV is strongly related to RT outcome end may reflect various prognosis for supraglottic tumors in a single T2 stage not only for local control effect but also for overall survival rate. Furthermore, TV should be considered as a predictor due to significant relation to other, tumor and host related factors. TV should be taken into consideration during treatment decision making process. It seems to be of spe- 
cial importance for larger tumors even when categorized as early disease according to TNM classification system.

The authors declare no conflict of interest.

\section{References}

1. Sessions DG, Lenox J, Spector GJ. Supraglottic laryngeal cancer: analysis of treatment results. Laryngoscope 2005; 115: 1402-10.

2. Mendenhall WM, Million RR, Cassisi NJ. Squamous cell carcinoma of the supraglottic larynx treated with radical irradiation: analysis of treatment parameters and results. Int J Radiat Oncol Biol Phys 1984; 10: 2223-30.

3. Goudakos JK, Markou K, Nikolaou A, Themelis C, Vital V. Management of the clinically negative neck (NO) of supraglottic laryngeal carcinoma: a systematic review. Eur J Surg Oncol 2009; 35: 223-9.

4. Rutkowski T. The role of tumor volume in radiotherapy of patients with head and neck cancer. Radiat Oncol 2014; 14: 9-23.

5. Studer G, Glanzmann C. Volumetric stratification of cT4 stage head and neck cancer. Strahlenther Onkol 2013; 189: 867-73.

6. Rutkowski T, Wygoda A, Składowski K, Hejduk B, Rutkowski R, Kołosza Z, Maciejewski B. Prognostic role of tumor volume for radiotherapy outcome in patient with T2 laryngeal cancer. Strahlenther Onkol 2013; 10: 861-6.

7. Kraas JR, Underhill TE, D’Agostino RB Jr, Williams DW 3rd, Cox JA, Greven KM. Quantitative analysis from CT is prognostic for local control of supraglottic carcinoma. Head Neck 2001; 23: 1031-6.

8. Mancuso AA, Mukherji SK, Schmalfuss I, Mendenhall W, Parsons J, Pameijer F, Hermans R, Kubilis P. Preradiotherapy computed tomography as a predictor of local control in supraglottic carcinoma. J Clin Oncol 1999; 17: 631-7.

9. Hamilton S, Venkatesan V, Matthews TW, Lewis C, Assis L. Computed tomographic volumetric analysis as a predictor of local control in laryngeal cancers treated with conventional radiotherapy. J Otolaryngol 2004; 33: 289-94.

10. Mukherji SK, Mancuso AA, Mendenhall W, Kotzur IM, Kubilis P. Can pretreatment CT predict local control of T2 glottic carcinomas treated with radiation therapy alone? AJNR Am J Neuroradiol 1995; 16: 655-62.

11. Lo SM, Venkatesan V, Matthews TW, Rogers J. Tumour volume: implications in T2/T3 glottic/supraglottic squamous cell carcinoma. J Otolaryngol 1998; 27: 247-51.

12. Bentzen SM, Thames HD. Tumor volume and local control probability: clinical data and radiobiological interpretations. Int J Radiat Oncol Biol Phys 1996; 36: 247-51.

13. Johnson CR, Thames HD, Huang DT, Schmidt-Ullrich RK. The tumor volume and clonogen number relationship: tumor control predictions based upon tumor volume estimates derived from computed tomography. Int J Radiat Oncol Biol Phys 1995; 33: 281 287.

14. Brenner DJ. Dose, volume, and tumor-control predictions in radiotherapy. Int J Radiat Oncol Biol Phys 1993; 26: 171-9.

15. Rutkowski T. Impact of initial tumor volume on radiotherapy outcome in patients with T2 glottic cancer. Strahlenther Onkol 2014; 190: 480-4.

16. Grabenbauer GG, Steininger $H$, Meyer M, et al. Nodal CT density and total tumor volume as prognostic factors after radiation therapy of stage III/IV head and neck cancer. Radiother Oncol 1998; 47: 175-83.

17. Hoebers FJ, Pameijer FA, de Bois J, Heemsbergen W, Balm AJ, Schornagel JH, Rasch CR. Prognostic value of primary tumor volume after concurrent chemoradiation with daily low-dose cis platin for advanced-stage head and neck carcinoma. Head Neck 2008; 30: 1216-23.

18. Chung EJ, Lee NJ, Baek SK, Kwon SY, Woo JS, Jung KY. Clinical efficacy of primary tumor volume measurements: comparison of different primary sites. Clin Exp Otorhinolaryngol 2009; 2: 78-84.

19. Kimura Y, Sumi M, Ichikawa Y, Kawai Y, Nakamura T. Volumetric MR imaging of oral, maxillary sinus, oropharyngeal, and hypopha- ryngeal cancers: correlation between tumor volume and lymph node metastasis. AJNR Am J Neuroradiol 2005; 26: 2384-9.

20. Ljungkvist AS, Bussink J, Rijken PF, Kaanders JH, van der Kogel AJ, Denekamp J. Vascular architecture, hypoxia, and proliferation in first-generation xenografts of human head-and-neck squamous cell carcinomas. Int J Radiat Oncol Biol Phys 2002; 54: 215-28.

21. Kuhnt T, Mueller AC, Pelz T, Haensgen G, Bloching M, Koesling S, Schubert J, Dunst J. Impact of tumor control and presence of visible necrosis in head and neck cancer patients treated with radiotherapy or radiochemotherapy. J Cancer Res Clin Oncol 2005; 131: 758-64.

22. Stadler P, Becker A, Feldmann HJ, Hänsgen G, Dunst J, Würschmidt $F$, Molls M. Influence of the hypoxic subvolume on the survival of patients with head and neck cancer. Int J Radiat Oncol Biol Phys 1999; 44: 749-54.

23. Dunst J, Stadler P, Becker A, Lautenschläger C, Pelz T, Hänsgen G, Molls M, Kuhnt T. Tumor volume and tumor hypoxia in head and neck cancers. The amount of the hypoxic volume is important. Strahlenther Onkol 2003; 179: 521-6.

24. Rutkowski T, Wygoda A, Składowski K, Hejduk B, Rutkowski R, Lukaszczyk-Widel B, Hutnik M, Maciejewski B. Predictors of radiotherapy outcome in patients with T2 supraglottic carcinoma. Eur Arch Otorhinolaryngol 2012; 269: 923-9.

25. Nordsmark M, Overgaard J. Tumor hypoxia is independent of hemoglobin and prognostic for loco-regional tumor control after primary radiotherapy in advanced head and neck cancer. Acta Oncol 2004; 43: 396-403.

26. Kats SS, Muller S, Aiken A, Hudgins PA, Wadsworth JT, Shin DM, Khuri F, Beitler JJ. Laryngeal tumor volume as a predictor for thyroid cartilage penetration. Head Neck 2013; 35: 426-30.

27. Chung CK, Stryker JA, Abt AB, Cunningham DE, Strauss M, Connor GH. Histologic grading in the clinical evaluation of laryngeal carcinoma. Arch Otolaryngol 1980; 106: 623-4.

28. Lohynska R, Slavicek A, Bahanan A, Novakova P. Predictors of local failure in early laryngeal cancer. Neoplasma 2005; 52: 483-8.

\section{Address for correspondence}

Tomasz Rutkowski, MD, PhD

Department of Radiotherapy and Chemotherapy

Maria Sklodowska-Curie Memorial

Cancer Center and Institute of Oncology

Gliwice Branch

Wybrzeże Armii Krajowej 15

44-100 Gliwice, Poland

tel. +48322788345

$\mathrm{fax}+48322788328$

e-mail: tomr22@tlen.pl

Submitted: 29.06.2014

Accepted: 1.08 .2014 